\title{
A survey on the management of acute rhinosinusitis among Asian physicians*
}

\author{
De-Yun Wang1, Retno S. Wardani², Kuljit Singh ${ }^{3}$, Sanguansak \\ Thanaviratananich ${ }^{4}$, Gil Vicente ${ }^{5}$, Geng Xu $\mathrm{X}^{6}$, Mohammed Rashid Zia ${ }^{7}$, Achal \\ Gulati $^{8}$, Sheen-Yie Fang ${ }^{9}$, Li Shi ${ }^{10}$, Yiong-Huak Chan ${ }^{11}$, David Price ${ }^{12}$, Valerie J. \\ Lund $^{13}$, Joaquim Mullol ${ }^{14}$, Wytske J. Fokkens ${ }^{15}$ \\ 1 Department of Otolaryngology, Yong Loo Lin School of Medicine, National University of Singapore, \\ Singapore \\ 2 Department of Otolaryngology, Faculty of Medicine University of Indonesia - Dr. Cipto Mangunkusumo \\ Hospital, Jakarta, Indonesia \\ 3 Department of Otorhinolaryngology, Prince Court Medical Centre, Kuala Lumpur, Malaysia \\ 4 Department of Otorhinolaryngology, Faculty of Medicine, Khon Kaen University, Thailand \\ 5 Department of Otolaryngology, St. Luke's Medical Centre, Quezon City, the Philippines \\ 6 Otorhinolaryngology Hospital, the First Affiliated Hospital of Sun Yat-sen University, Guangzhou, China \\ 7 Department of Otolaryngology Head \& Neck Surgery, Jinnah Hospital, Allama Iqbal Medical College, \\ Lahore, Pakistan \\ 8 Department of Otolaryngology Head \& Neck Surgery, Maulana Azad Medical College, New Delhi, India \\ 9 Department of Otolaryngology, Chiali Medical Corporation Aggregate Chiali Hospital, Tainan,Taiwan \\ ${ }^{10}$ Department of Otolaryngology, Qilu Hospital, Shandong University, China \\ 11 Biostatistical Unit, Yong Loo Lin School of Medicine, National University of Singapore, Singapore \\ ${ }_{12}$ Centre of Academic Primary Care, University of Aberdeen, Aberdeen, United Kingdom \\ ${ }^{13}$ Institute of Laryngology and Otolaryngology, University College London, London, United Kingdom \\ ${ }^{14}$ Rhinology Unit \& Smell Clinic, ENT, Department, Hospital Clinic - IDIBAPS, CIBERES, Barcelona, \\ Catalonia, Spain \\ ${ }^{15}$ Department of Otorhinolaryngology, Amsterdam Medical Centre, Amsterdam, the Netherlands
}

SUMMARY

Background: Based on the 'European Position Paper on Rhinosinusitis and Nasal polyps (EP3OS 2007)', this study aimed to investigate general practitioners (GPS) and other specialists' understanding when managing patients with acute rhinosinusitis ( ARS) in Asia.

Methodology: Among a total of 2662 questionnaires completed, 2524 (94.8\%) were valid for analysis. There were 1308 GPS (51.8\%), 989 otolaryngologists (39.2\%) and 227 paediatricians (9\%) from Mainland China, Hong Kong, Indonesia, India, Malaysia, Pakistan, Philippines, Singapore, Thailand and Taiwan.

Results: ARS is affecting an estimated $6-10 \%$ of patients seen in a daily out-patient practice. The EP $P^{3}$ S criteria are well supported by Asian physicians (94.1\%). Most physicians (62.7\%) agreed that radiological investigation is not needed to diagnose ARS. However, even for mild ARS (common cold), medical treatments were still recommended by $87 \%$ of GPs, $83.9 \%$ of otolaryngologists, and $70 \%$ of paediatricians. The top three first-line treatments prescribed were antihistamines (39.2\%), nasal decongestants (33.6\%), and antibiotics (29.5\%). Antibiotics usage increased as the first line treatment of moderate (45.9\%) and severe $(60.3 \%)$ ARS.

Conclusion: ARS is commonly managed by GPs, otolaryngologists, and paediatricians in Asia. However, understanding of the management of ARS needs further improvement to minimize unnecessary use of radiological investigations, overuse of antibiotics, and under use of nasal corticosteroids.

Key words: acute rhinosinusitis, Asia, EP $P^{3} \mathrm{OS}$, diagnosis, treatment, antibiotics, nasal corticosteroids

\section{INTRODUCTION}

Acute rhinosinusitis (ARS) is a significant health problem, being one of the top reasons for a visit to primary care clinics ${ }^{(1)}$. It was found that an average of $8.4 \%$ of the Dutch population reported at least one episode of ARS per year in
$1999^{(2)}$. The incidence of visits to the general practitioner for acute rhinosinusitis in the Netherlands in 2000 was 20 per 1000 men and 33.8 per 1000 women ${ }^{(3)}$. According to data from a National Ambulatory Medical Care Survey (NAMCS) in the USA, rhinosinusitis is the fifth most common diagnosis 
for which an antibiotic is prescribed. In 2002, rhinosinusitis accounted for $9 \%$ and $21 \%$ of all paediatric and adult antibiotic prescriptions, respectively ${ }^{(4)}$.

ARS is a condition characterized by inflammation of the nasal and sinus tissues, classically occurring 5 to 7 days after a viral upper respiratory tract infection (URTI) ${ }^{(1)}$. Recently, an evidence-based guideline entitled 'European Position Paper on Rhinosinusitis and Nasal polyps (EP ${ }^{3} \mathrm{OS}$ in 2007)' has been published to enhance the effectiveness and quality of management for ARS patients ${ }^{(1,5)}$. However, the impact of these guidelines on the physician's management of ARS patients has not been assessed, neither in Asian countries.

The purpose of this survey study was to investigate the opinions of Asian general practitioners (GPs) and other specialists (e.g., otolaryngologists and paediatricians) when diagnosing and treating patients with primary ARS. We also wanted to determine if there was any difference in the management of ARS at the local level in Asia versus $\mathrm{EP}^{3} \mathrm{OS}$ recommendations.

\section{METHODS}

The study design and questionnaire have been approved by the Institutional Review Board of the National University of Singapore.

\section{Study questionnaire}

The questionnaire was originally designed in English (Appendix 1), and a professional translation to Chinese was also provided for subjects who did not speak English in Mainland China and Taiwan. The questionnaire included information about the medical practice (e.g., type and year of practice), gender and age of the physicians surveyed, concepts or diagnostic criteria of ARS and treatment based on $\mathrm{EP}^{3} \mathrm{OS}$ recommendations (the original copy of the questionnaire is attached).
Study design

A copy of the $\mathrm{EP}^{3} \mathrm{OS}$ pocket guide was provided to each physician who agreed to be surveyed. The initial plan of this study was to survey primary care physicians (or GPs) who treat patients with ARS using their professional societies and existing CME (Continuing Medical Education) programs during the period of May to November 2008. An invitation letter explaining the nature of this survey was attached to each questionnaire, together with a return envelope to the principle investigator of this study. Personal data such as name, contact and mail address were treated as confidential and completion was optional for participants in the survey.

A total of 8 countries with 10 investigating sites were surveyed: Mainland China, Hong Kong, Indonesia, India, Malaysia, Pakistan, Philippines, Singapore, Thailand, and Taiwan. Due to the difference in healthcare systems governed by the medical authorities in these countries, patients with ARS may be able to visit otolaryngology or paediatric clinics directly without a referral from the primary care physicians. Because of this, otolaryngologists and paediatricians were also surveyed if they were treating ARS in a primary care setting, such as in Mainland China, Taiwan, Thailand, and India.

\section{Statistical analysis}

All statistical tests were carried out using a two-tailed method and a $5 \%$ level of significance $(\mathrm{p}<0.05)$. The calculations were performed using the SPSS program PASW Statistical 17.0. Descriptive statistics were presented as \% (n). The ChiSquare test or Fisher's Exact test was used to investigate the relationships between categorical variables. Tests were carried out to investigate the existence of relationships between different specialties (e.g., GPs, otolaryngology and paediatrician), the type of medical practice (e.g., type and years of practice, gender and age of the physicians) and their opinions in diagnosis and management of ARS (e.g., the use of antibiotics and other treatment modalities). Bonferroni adjustments were made for the pairwise comparisons.

Table 1. Summary of demographic information of the physicians surveyed in the study $(n=2524)$.

\begin{tabular}{|c|c|c|c|c|c|c|c|c|c|c|c|c|}
\hline \multirow{2}{*}{ Country/Region } & \multirow{2}{*}{$\begin{array}{l}\text { Subject } \\
\%(\mathrm{~N})\end{array}$} & \multirow{2}{*}{$\begin{array}{l}\text { Males } \\
\%(\mathrm{~N})\end{array}$} & \multicolumn{4}{|c|}{ Age (years) (\%) } & \multicolumn{3}{|c|}{ Type of practice $(\%)$} & \multicolumn{3}{|c|}{ Years of practice $(\%)$} \\
\hline & & & $<30$ & $30-39$ & $40-49$ & $>50$ & GP & ENT & Ped & $<5$ & $5-10$ & $>10$ \\
\hline China (mainland) & $11.1(282)$ & $60(169)$ & 5.1 & 32.9 & 40.9 & 21 & 1.0 & 93.9 & 4.9 & 5.7 & 13.2 & 81.1 \\
\hline Hong Kong & $1.1(28)$ & $96(27)$ & 0 & 40.7 & 29.6 & 29.6 & 71.4 & 21.4 & 7.1 & 0 & 21.4 & 78.6 \\
\hline Indonesia & $27(682)$ & $53(363)$ & 14.1 & 34.6 & 25.1 & 26.2 & 70.1 & 18.3 & 11.6 & 37.2 & 23.3 & 39.5 \\
\hline India & $12.4(313)$ & $92(288)$ & 1.3 & 26.5 & 35.1 & 37.1 & 38.6 & 60.7 & 0.6 & 7.1 & 19.6 & 73.2 \\
\hline Malaysia & $14.4(364)$ & $51(184)$ & 4.9 & 32.9 & 35.2 & 26.9 & 76.4 & 16.7 & 6.8 & 14 & 25.3 & 60.7 \\
\hline Pakistan & $2.3(60)$ & $93(56)$ & 13.3 & 23.3 & 45 & 18.3 & 60.0 & 38.3 & 1.6 & 16.6 & 28.3 & 55 \\
\hline Philippines & 10.9 (277) & $35(97)$ & 18.9 & 41.1 & 27.4 & 12.6 & 46.6 & 28.9 & 24.5 & 41.5 & 27.4 & 31.1 \\
\hline Singapore & 7.5 (189) & $60(113)$ & 8.5 & 35.4 & 35.4 & 20.6 & 96.8 & 0.5 & 2.6 & 16.4 & 22.9 & 60.3 \\
\hline Thailand & $8.1(204)$ & $41(84)$ & 31.9 & 43.6 & 15.7 & 8.6 & 17.6 & 74.4 & 8 & 45.9 & 31.3 & 22.7 \\
\hline Taiwan & $4.9(125)$ & 94 (117) & 8.4 & 56.5 & 27.5 & 7.6 & 19.1 & 68.7 & 12.2 & 19.1 & 41.2 & 39.6 \\
\hline Sub-total & $100(2524)$ & 59 (1498) & 11.2 & 35.6 & 30.5 & 22.7 & 51.8 & 39.2 & 9.0 & 24.4 & 24.1 & 51.5 \\
\hline
\end{tabular}


Table 2. Percentage (\%) of drugs used by physicians depending on disease severity.

\begin{tabular}{|c|c|c|c|c|c|c|c|c|c|}
\hline \multirow[t]{2}{*}{ Drugs } & \multicolumn{2}{|c|}{ Mild ARS } & \multirow[b]{2}{*}{ Ped } & \multicolumn{2}{|c|}{ Moderate ARS } & \multicolumn{4}{|c|}{ Severe ARS } \\
\hline & GP & ENT & & GP & ENT & Ped & GP & ENT & Ped \\
\hline Decongestants & 87.6 & 89.2 & 96.1 & 79.3 & 83.9 & 87.3 & 77.2 & $87.8^{\dagger}$ & 84.1 \\
\hline Antibiotics & 72.8 & $89.1^{*}$ & 68.1 & 87 & $96.5^{\dagger}$ & 83.2 & 92.0 & 96.8 & 97.3 \\
\hline Oral Antihistamines & 91.7 & 75.1 & 100.0 & 81.9 & $68.1^{*, \dagger}$ & 82.7 & 82.7 & 70.4 & 88.2 \\
\hline Pain relief & 72.3 & 65.6 & 58.4 & 69.8 & 60.9 & 51.8 & 78.8 & 72.3 & 72.7 \\
\hline Nasal douche & 22.9 & $46.1^{* \dagger}$ & 46.8 & $21.0^{\ddagger}$ & $47.9^{*}$ & 38.6 & 24.8 & 51.0 & 39.5 \\
\hline Nasal corticosteroids & 45.3 & 61.3 & 52.6 & 49.9 & 62.8 & 55.9 & 56.1 & 65.9 & 67.3 \\
\hline Topical antibiotics & 16.4 & 19.1 & 14.3 & 13.2 & 17.1 & 11.8 & 13.3 & 18.7 & 14.1 \\
\hline Systemic steroids & 32.1 & 28.6 & 24.7 & 33.5 & 29.4 & 22.7 & 42.4 & 40.8 & 34.1 \\
\hline Mucolytics & 61.9 & 69.4 & 66.9 & 56.2 & 68.5 & 57.7 & 60.6 & 71.3 & 61.3 \\
\hline Herbal medicine & 13.1 & 24.1 & 14.3 & 10.1 & $20.6^{\dagger}$ & 13.6 & 10.4 & 19.9 & 10.9 \\
\hline
\end{tabular}

There is no significant difference between gender, year of practice, or age of the physicians

$*: \mathrm{p}<0.05$ ENT vs Ped;

$\dagger: \mathrm{p}<0.05$ ENT vs GP

†: $<<0.05$ Ped vs GP

\section{RESULTS}

Among a total of 4000 questionnaires distributed, 2662 surveys were duly completed and returned (mean response rate of $66.5 \%)$, of which $2524(94.8 \%)$ questionnaires were valid for analysis. One hundred and thirty-eight surveys were not included for analysis due to missing information as to the type of medical practice. The details of the number of physicians surveyed at different investigational sites (countries), their gender and age distributions, the type and years of practice are listed in Table 1. Of them, 1308 (51.8\%) were GPs, 989 (39.2\%) otolaryngologists, and $227(9 \%)$ paediatricians. Half of the physicians $(51.5 \%)$ surveyed had more than 10 years of clinical experience.

\section{Agreement with $\mathrm{EP}^{3} \mathrm{OS}$ 's diagnostic criteria}

Two thousand three hundred seventy-five (94.1\%) of the physicians agreed with the diagnostic criteria for ARS recommended by the $\mathrm{EP}^{3} \mathrm{OS}{ }^{(1)}$. Only 149 physicians (5.9\%) felt that the recommendation could lead to over diagnosis ( $\mathrm{n}$ $=102,4 \%)$ or under diagnosis $(n=47,1.9 \%)$ of ARS. There was no significant difference between the answers of GPs, otolaryngologists and paediatricians.

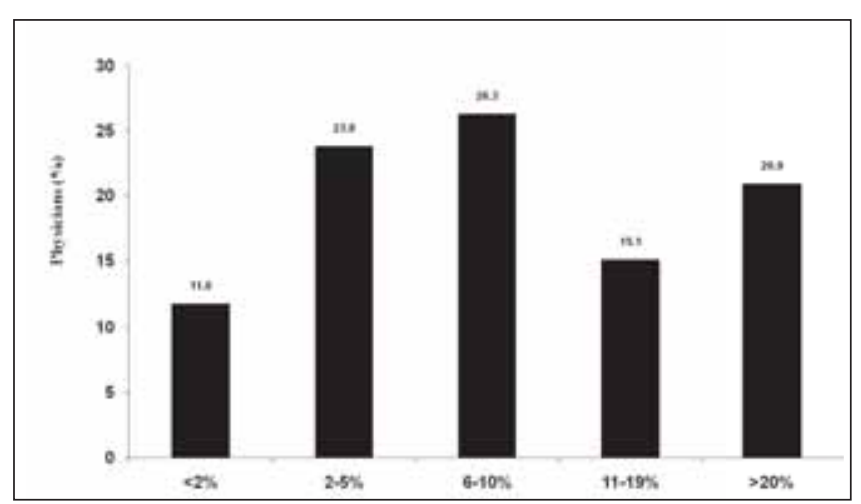

Figure 1. Incidence of acute rhinosinusitis (ARS).
The use of radiological investigations

It was recommended by $\mathrm{EP}^{3} \mathrm{OS}$ that radiological investigations (e.g., plain X-ray and CT scan) are not indicated unless additional problems are present, such as very severe disease, immunocompromised patients and/or signs of complications. This recommendation was well supported by 1847 (73.2\%) of the physicians. However, for 677 (26.8\%) physicians, a plain X-ray $(\mathrm{n}=475,18.8 \%)$ or CT scan $(\mathrm{n}=202,8 \%)$ was still requested.

In this survey, physicians were asked to estimate the percentage $(<2 \%, 2-5 \%, 6-10 \%, 11-19 \%$ or $>20 \%)$ of patients who had been diagnosed with ARS over a one-year period in their clinics. It showed that the overall and highest range given was $6-10 \%$ (Figure 1). However, 246 otolaryngologists (24.9\%) indicated that more than $20 \%$ of the patients seen in their clinics were for ARS, which was higher than the GPs ( $n=232$, $17.8 \%)$ and paediatricians $(\mathrm{n}=30,13.2 \%)$. The most common

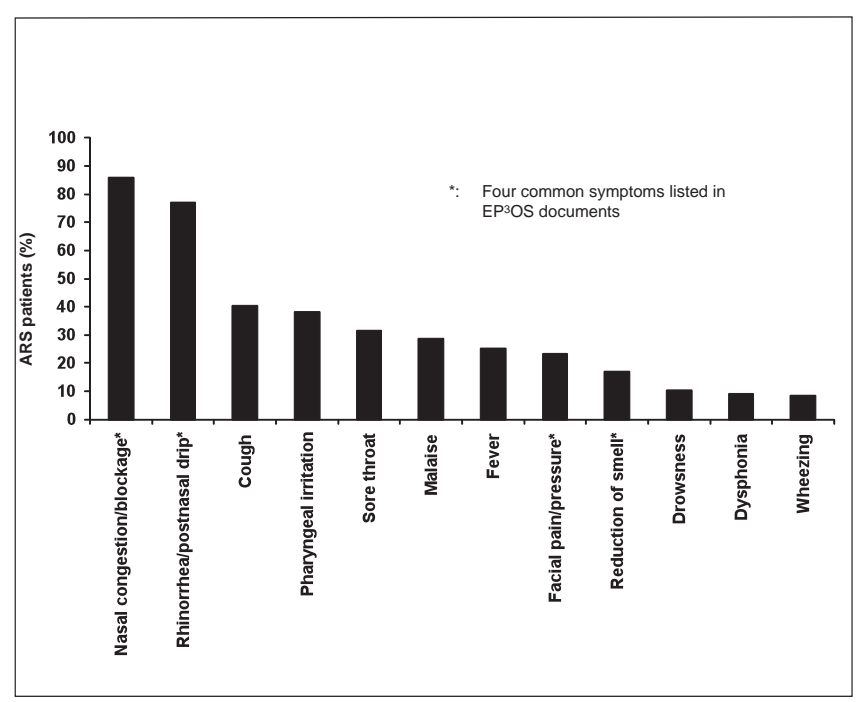

Figure 2. Most common characteristics in ARS. 
Table 3. The top three drugs used as first-line treatment by physicians. There is no significant difference in respect to gender, year of practice, or age of the physicians.

\begin{tabular}{lcccc}
\hline Severity & Antibiotics & $\begin{array}{c}\text { Oral antihis- } \\
\text { tamines }\end{array}$ & Decongestants & Pain relief \\
\hline Mild & $29.5 \%$ & $39.2 \%$ & $33.6 \%$ & - \\
Moderate & $45.9 \%$ & $37.2 \%$ & $32.5 \%$ & - \\
Severe & $60.3 \%$ & $37.6 \%$ & - & $38.4 \%$ \\
\hline
\end{tabular}

presenting symptoms of ARS to physicians are listed in Figure 2.

\section{Classifications of the severity of ARS}

In $\mathrm{EP}^{3} \mathrm{OS}$, the severity of ARS is divided into mild, moderate and severe based on a total severity visual analogue scale $($ VAS, $0-10 \mathrm{~cm}):$ MILD = VAS $0-3$; MODERATE $=$ VAS > $3-7$; and SEVERE = VAS $>7-10^{(1)}$. However, in the $\mathrm{EP}^{3} \mathrm{OS}$ pocket guide, a clinical classification has also been introduced in the evidence-based management scheme: MILD = common cold or symptoms less than 5 days; MODERATE $=$ presenting symptoms worsening after 5 days or lasting for more than 10 days, but with no fever and no severe facial pain; SEVERE $=$ presenting symptoms worsening after 5 days or lasting for more than 10 days with fever $>38^{\circ} \mathrm{C}$ and severe facial pain. Most physicians, $77.1 \%$ of GPs, $68.7 \%$ of otolaryngologists and $79.7 \%$ of paediatricians favoured the clinical severity classification of ARS.

\section{Medical treatment of ARS}

Based on the severity of ARS, the participants were asked to rank their choice of common medical treatments (e.g., pain relief, antibiotics, topical antibiotics, systemic corticosteroids, nasal corticosteroids, oral antihistamines, decongestants, nasal douche (washes), mucolytics, herbal medicine and others) from 1 (most often) to 10 (least often).

For patients with mild ARS, most GPs ( $\mathrm{n}=1138,87 \%)$, otolaryngologists $(n=830,83.9 \%)$ and paediatricians $(n=159$, $70 \%$ ) indicated that they would provide some type of medical treatment (Figure 3, Table 2) for their patients. There was a statistically $(\mathrm{p}<0.05)$ more frequent use of antibiotics by otolaryngologists $(89.1 \%)$ than paediatricians $(68.1 \%)$. There was no statistical difference of antibiotic use between different investigational sites (countries), nor difference between physicians according to gender, year of practice or age. Nasal douche was recommended significantly less $(p<0.05)$ by GPs $(22.9 \%)$ than otolaryngologists $(46.1 \%)$ and paediatricians (46.8\%). For patients with moderate ARS (Figure 3, Table 2), $96.5 \%$ of otolaryngologists recommended the use of antibiotics, which is statistically higher $(\mathrm{p}<0.05)$ than GPs $(87 \%)$ and paediatricians $(83.2 \%)$. Oral antihistamines were more frequently $(\mathrm{p}<0.05)$ used by paediatricians $(82.7 \%)$ and GPs $(81.9 \%)$ than otolaryngologists $(68.1 \%)$. However, nasal corticosteroids were less commonly used than other medications by GPs (49.9\%), otolaryngologists (62.8\%) and

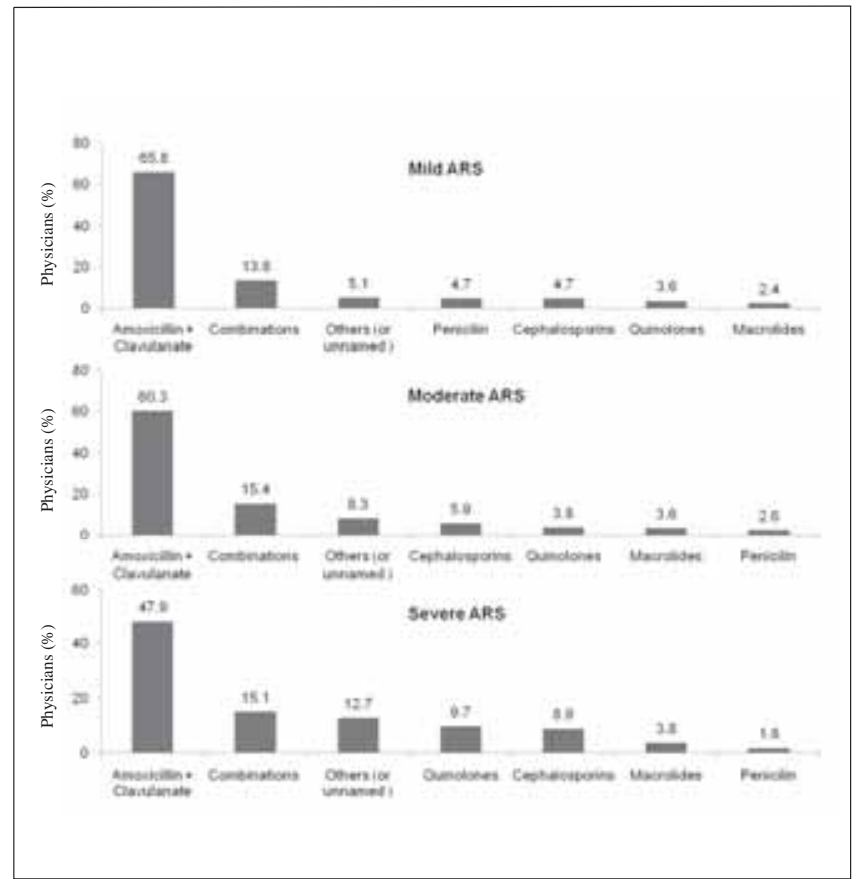

Figure 3. Use of antibiotics depending on disease severity. paediatricians $(55.9 \%)$.

For patients with severe ARS (Table 2), antibiotic treatment was the top choice for treatment provided by GPs (92\%), otolaryngologists $(96.8 \%)$ and paediatricians $(97.3 \%)$. There was no statistical difference between the medical treatments provided by all three groups of physicians from the different investigational sites, nor any difference between physicians in regards to gender, year of practice or age.

Table 3 summarises the frequency of the top three medical treatments selected by physicians in patients with different severities of ARS. Figure 3 shows the type of antibiotics, which are recommended by physicians in mild, moderate, and severe ARS. In total, $55.6 \%$ of GPs and $57.7 \%$ of paediatricians have indicated that they would treat patients with moderate ARS and refer the patients to otolaryngologists if there was no improvement after 14 days of treatment. However, for more than $83 \%$ of the GPs and paediatricians, they would refer the patients to an otolaryngologist immediately if the symptoms are severe and especially if they showed ocular or neurological complications.

\section{DISCUSSION}

Rhinosinusitis in its various forms, constitutes one of the commonest conditions encountered in medical practice and may present to a wide range of clinicians ${ }^{(1)}$. Although the incidence of ARS is very high, ranging from acute viral (common cold) to severe bacterial rhinosinusitis, there is very limited data on the epidemiology and understanding of the management of ARS among different specialties, commonly treating ARS. Thanks to the introduction of $\mathrm{EP}^{3} \mathrm{OS}$ documents, we were able to perform a multi-centre study on ARS, based on a uniformly accepted definition. Although this is not a population-proportionately stratified random sampling study, we were able to obtain large number of physicians (GPs 
and other specialists) from each country, among which, their opinions on the management of ARS appear to be similar. This is the first study reporting this important healthcare issue in Asia.

From our data, $6-10 \%$ of the total outpatient visits are associated with ARS. Although this figure could be overestimated due to a retrospective estimation, it confirms that ARS is common in both GPs and other specialist clinics (otolaryngology and paediatrics). In general, most physicians surveyed agreed with the definition and diagnostic criteria for ARS, as suggested by the $\mathrm{EP}^{3} \mathrm{OS}$ recommendations. The diagnosis of uncomplicated ARS is defined as increasing symptoms after 5 days or persistent symptoms for 10 days for less than 12 weeks in duration ${ }^{(1)}$. Radiological investigation is not recommended unless additional problems are present, such as severe symptoms, immunocompromised patients or signs of complications. However, from our survey, a number of physicians $(n=677,26.8 \%)$ still used plain X-ray $(n=475$, $18.8 \%)$ or CT scan $(n=202,8 \%)$ on a regular basis. It could be one of the explanations that plain X-ray is still popular among the GPs and other specialists in Asia as a screening tool in clinical practice. However, the perceived need of radiological investigation results in unnecessary patient exposure to radiation and increased healthcare costs.

The most alarming finding in this study is antibiotics overusage by GPs, otolaryngologists and paediatricians in patients with ARS. Antibiotic therapy should be reserved for patients with severe symptoms who meet the criteria for clinical diagnosis of acute bacterial rhinosinusitis and for those with severe rhinosinusitis symptoms, such as unilateral facial pain and/or fever $>38^{\circ} \mathrm{C}$ regardless of the duration of symptoms ${ }^{(6)}$. This practical recommendation has been reinforced by $\mathrm{EP}^{3} \mathrm{OS}{ }^{(1)}$. Our data shows that antibiotics are still prescribed by $65.8 \%$ of the physicians surveyed. Even more alarmingly, $13.6 \%$ of the participants used a combination of more than two antibiotics classes (Figure 3) for treatment of even mild ARS. Antibiotics overusage has been reported in some European countries $(7,8)$, to have directly resulted in an increased prevalence of antimicrobial resistance in Europe ${ }^{(9,10)}$. Although such data is still unavailable in Asia, the global threat posed by resistant microorganisms has become an international health issue, product of careless antibiotics abuse.

In the literature, among more than 2000 studies on the antibiotic treatment of ARS published, only 49 involving 13,660 participants meet the Cochrane Board criteria for placebo control, statistical analysis, sufficient sample size and the description of clinical improvement or successful treatment ${ }^{(1,11)}$. In a recent Cochrane Review paper, the authors concluded that antibiotics have only a moderate effect in patients with uncomplicated ARS, in a primary care setting with symptoms for more than seven days. Since $80 \%$ of ARS patients treated without antibiotics improve within two weeks, clinicians need to weigh the moderate benefits of antibiotics against its potential for adverse consequences at both the individual and global level ${ }^{(11)}$.

Surprisingly the study results showed that oral antihistamines are the most frequently prescribed drugs, especially for mild ARS. Antihistamines are standard treatment for IgE-mediated allergic diseases such as allergic rhinitis, where histamine (released by mast cells and basophils) is one of the major effectors of allergic reaction ${ }^{(12,13)}$. The pathophysiology of ARS is felt to be secondary bacterial infection due to the impairment of mechanical, humoral and cellular defenses and epithelial damage caused by viral infection (common cold) ${ }^{(1)}$. There is no indication for the use of antihistamines ARS treatments, except in co-existing allergic rhinitis.

In the $\mathrm{EP}^{3} \mathrm{OS}$ document, intranasal corticosteroids are recommended for the treatment of ARS, both in the moderate (in monotherapy) and severe (with oral antibiotics) disease ${ }^{(14)}$. The introduction of topically administered glucocorticoids has improved the treatment of the upper (rhinitis, rhinosinusitis with and without nasal polyps) and lower (asthma) airway inflammatory disease. The clinical efficacy of glucocorticoids depends on their anti-inflammatory properties and ability to promote epithelial repair ${ }^{(1,15,16)}$.

Most studies on corticosteroids in ARS have determined the effect of topical corticosteroids when used as adjunct therapy to antibiotics. Recently, a few studies were able to show a better efficacy of nasal corticosteroid when used as a monotherapy alone than antibiotics in the treatment of ARS ${ }^{(17-19)}$. However, further randomized clinical studies are needed to study the efficacy and appropriate use of antibiotics and nasal steroids as mono-or combined therapy in the treatment of ARS, with different severities.

In conclusion, this is the first study that demonstrates the high prevalence of ARS and its encounter by GPs, otolaryngologists and paediatricians in Asia. The diagnostic criteria in the $\mathrm{EP}^{3} \mathrm{OS}$ document are well supported by Asian physicians. However, the actual management of ARS such as the unnecessary use of radiological investigations, over-usage of antibiotics and under-usage of nasal corticosteroids needs to be changed. Appropriate physicians education promoting better understanding of the nature of ARS and evidencedbased diagnostic and treatment options will improve treatment outcomes, and plays an important role in combating the emerging healthcare issue resulting from the rising global antimicrobial resistance.

\section{ACKNOWLEDGEMENT}

The authors wish to thanks Mr. Goh Wei Leong, research coordinator in the department of otolaryngology for his kind assistance in data collection and entry for this study. We also wish to thank Professor James Smith for kindly reviewing this paper.

Declaration of all sources of funding: A partial unrestricted 
educational fund provided by Schering-Plough for printing and mailing surveys.

\section{CONFLICT OF INTEREST}

No conflicts of interest for all authors.

\section{REFERENCES}

1. Fokkens W, Lund V, Mullol J. European position paper on rhinosinusitis and nasal polyps 2007. Rhinology 2007. Suppl. 20: $1-136$

2. Giesbers HrNo-IVTV, Nationale Atlas Volksgezondheid. Bilthoven: RIVM, < Gezondheid\Ziekten en aandoeningen\ Ziekten van de ademhalingswegen, 27 september 2002. Neusbijholte ontsteking 1995-1999. 2002 cited; Available from: http://www.zorgatlas.nl

3. Gijsen R, Poos M. Nationaal Kompas. 2003 cited; Available from: Fokkens W, Lund V, Mullol J, on behalf of the European Position Paper on Rhinosinusitis and Nasal Polyps group. European position paper on rhinosinusitis and nasal polyps 2007. Rhinology. 2007; Supplement 20: 1-136.

4. Anon JB, Jacobs MR, Poole MD, Ambrose PG, Benninger MS, Hadley JA, et al. Antimicrobial treatment guidelines for acute bacterial rhinosinusitis. Otolaryngol Head Neck Surg. 2004; 130(1 Suppl): 1-45.

5. Thomas M, Yawn BP, Price D, Lund V, Mullol J, Fokkens W. EPOS Primary Care Guidelines: European Position Paper on the Primary Care Diagnosis and Management of Rhinosinusitis and Nasal Polyps 2007 - a summary. Prim Care Respir J. 2008; 17: 79-89.

6. Hickner JM, Bartlett JG, Besser RE, Gonzales R, Hoffman JR, Sande MA. Principles of appropriate antibiotic use for acute rhinosinusitis in adults: background. Ann Intern Med. 2001; 134: 498-505.

7. Cars O, Mõlstad S, Melander A. Variation in antibiotic use in the European Union. Lancet. 2001; 357: 1851-1853.

8. Wise R, Hart T, Cars O. Streulens M, Helmuth R, Huovinen P, et al. Antimicrobial resistance. Is a major threat to public health. BMJ. 1998; 317: 609-610.

9. Felmingham D, Reinert RR, Hirakata Y, Rodloff A. Increasing prevalence of antimicrobial resistance among isolates of Streptococcus pneumoniae from the PROTEKT surveillance study, and compatative in vitro activity of the ketolide, telithromycin. J Antimicrob Chemother. 2002; 50 Suppl S1: 25-37.

10. Goossens H, Ferech M, Vander Stichele R, Elseviers M. Outpatient antibiotic use in Europe and association with resistance: a cross-national database study. Lancet. 2005; 365: 579587.

11. Williams JW Jr, Aguilar C, Cornell J, Chiquette E, Dolor RJ, Makela M, Holleman DR, et al. Antibiotics for acute maxillary sinusitis Cochrane Database Syst Rev. 2003: CD000243.

12. Bousquet J, Van Cauwenberge P, Khaltaev N. Allergic rhinitis and its Impact on Asthma. J Allergy Clin Immunol. 2001; 108 (5 Suppl): S147-334.

13. Bousquet J, Khaltaev N, Cruz AA, Denburg J, Fokkens WJ, Togias A, et al. Allergic rhinitis and its Impact on Asthma (ARIA) 2008 Update. Allergy. 2008; 63 (Suppl 86): 1-160.

14. Mullol J, Obando A, Pujols L, Alobid I. Corticosteroid treatment in chronic rhinosinusitis: the possibilities and the limits. Immunol Allergy Clin North Am. 2009; 29: 657-668.

15. Li CW, Cheung W, Lin ZB, Li TY, Lim JT, Wang DY Oral steroids enhance epithelial repair in nasal polyposis via up-regulation of AP-1 gene network. Thorax. 2009; 64; 306-312.

16. Zalmanovici A, Yaphe J. Intranasal steroids for acute sinusitis. Cochrane Database Syst Rev. 2009: CD005149.

17. Meltzer EO, Bachert C, Staudinger H. Treating acute rhinosinusitis: comparing efficacy and safety of mometasone furoate nasal spray, amoxicillin, and placebo. J Allergy Clin Immunol. 2005; 116: 1289-1295.

18. Bachert C, Meltzer EO. Effect of mometasone furoate nasal spray on quality of life of patients with acute rhinosinusitis. Rhinology. 2007; 45: 190-196.

19. Williamson IG, Rumsby K, Benge S, Moore M, Smith PW, Cross $\mathrm{M}$, et al. Antibiotics and topical nasal steroid for treatment of acute maxillary sinusitis: a randomized controlled trial. JAMA. 2007; 298: 2487-2496.

De Yun Wang, MD, PhD

Department of Otolaryngology

Yong Loo Lin School of Medicine

National University of Singapore

Singapore

Tel: $+65-67-725373$

Fax: +65-67-753 820

E-mail: entwdy@nus.edu.sg 

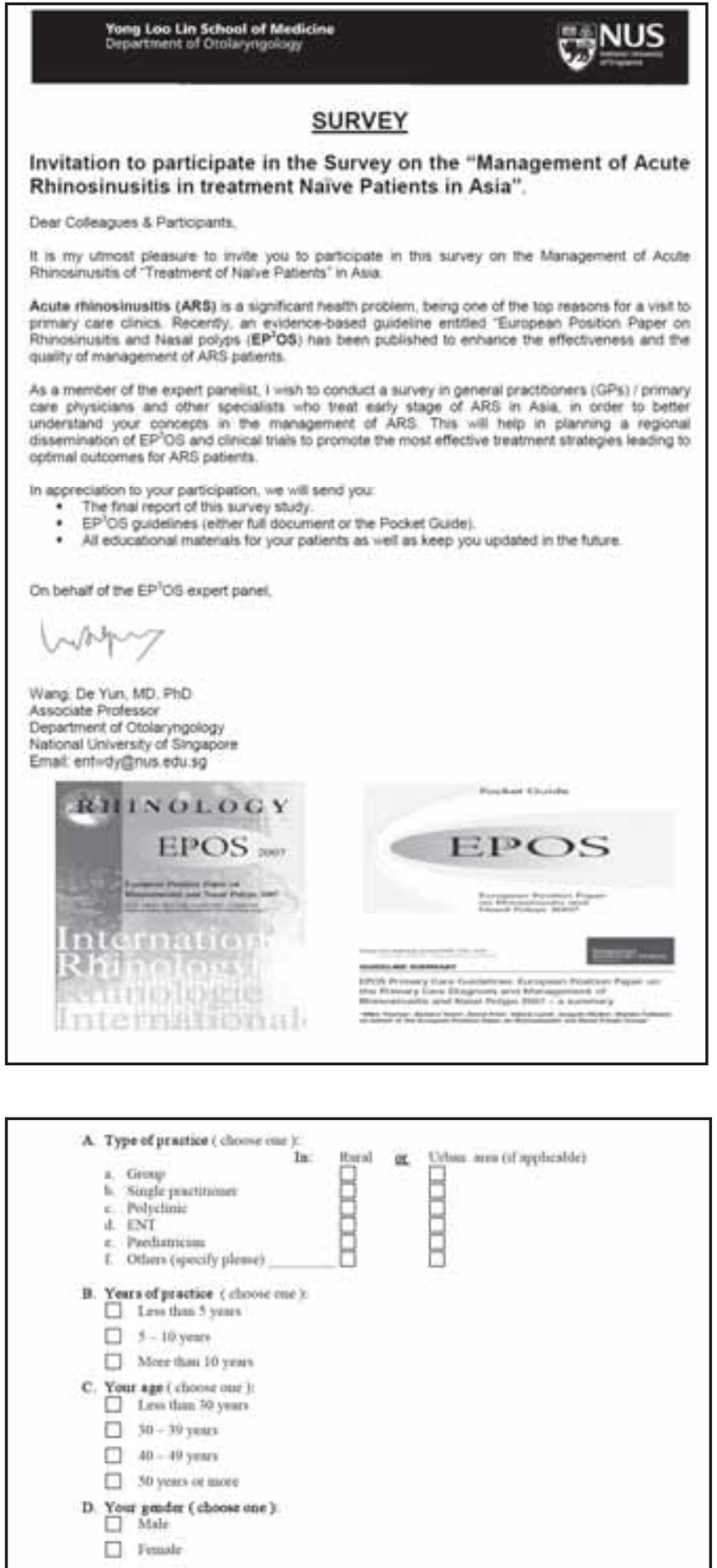





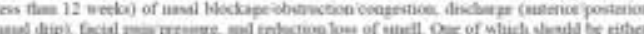



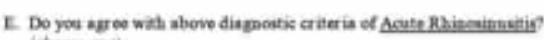

throne ine:

Qq to quatiuse $\mathrm{C}$

口 Not

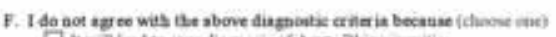



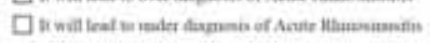

Manascement of Acste Rhinosinuritis in treatmest Naive Patients in Asis.

Name of Practitioner:

Address of Practice.

- Email Aduress:

Date:

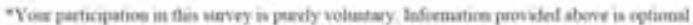




confidential
Meaic indicate what you will ceavider to be the rwo key nymptoma (you may refer to

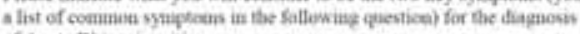
of Actle Rhinamimative

G. How offen do the patients in you clinic with Acute Rhinosinuvitis experience each of the follewing sympteens? (Cledk all that apply.)

\begin{tabular}{|c|c|}
\hline Alockape obatruction conpestion & $\square$ offen, $\square$ wometimes, $\square$ never \\
\hline t. Disctartze (anteriar ponteriat nanal thip) & Daften. Divmartimes, Darver \\
\hline c. Focial pain yrensue & 口often, , penefimes: $\square$ neve \\
\hline d. Reduction low of uneti &  \\
\hline 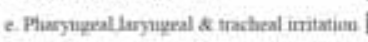 & $\square$ aften, $\square$ unemetimes, $\square$ us \\
\hline I. Soce theot & 口offen, 口uemetimes. $\square$ nev \\
\hline 1. Dyyphonia & Doffen. Quventimes, Dicv \\
\hline h. Cough & Dotten, Durmartimes, $\square$ nes \\
\hline i. Dewnines &  \\
\hline 1. Malaise & 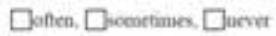 \\
\hline k. Fever & 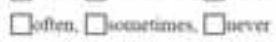 \\
\hline 1. Wheermy & $\square$ often, $\square$ womstimes, $\square \mathrm{men}$ \\
\hline in. Othen qule & Qutten. Duenortimes \\
\hline
\end{tabular}

H. Approximately what percentage of your total patimts has tad a dingnosis of Acule Rhinoginusitin over a 1 year period? (choose one)

$\square<2$

口2.5\%

口6-10\%

口11-199.

口 300. co inse

1. Usually Acute Rhisosinusitia patiests visit your clinic when (Circle all itsat apgly.)



口 Their vymproma have ase uitsided after mose thau 5 dys

$\square$ They have a fever above $38^{\circ} \mathrm{C}$

$\square$ They have severe facial pain

They porsent with ceepipticabous such as 


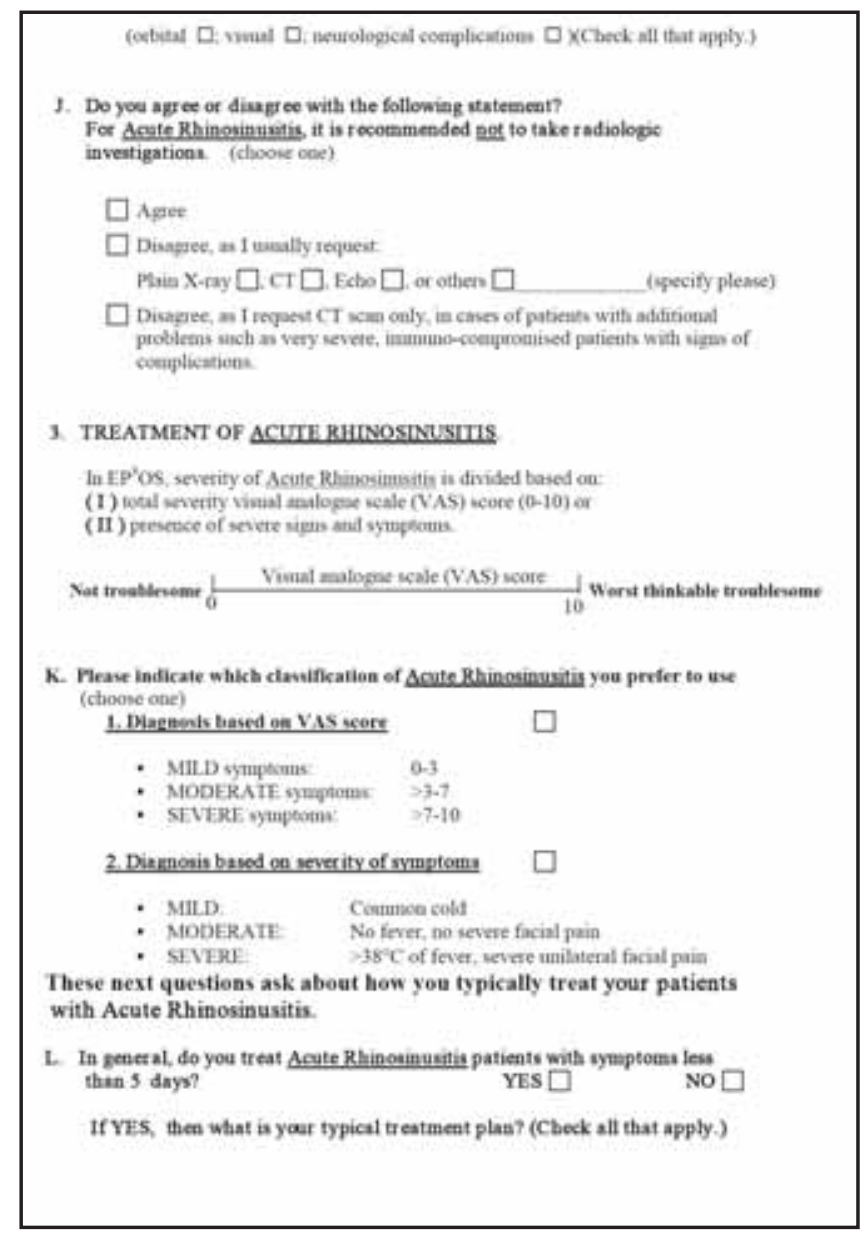

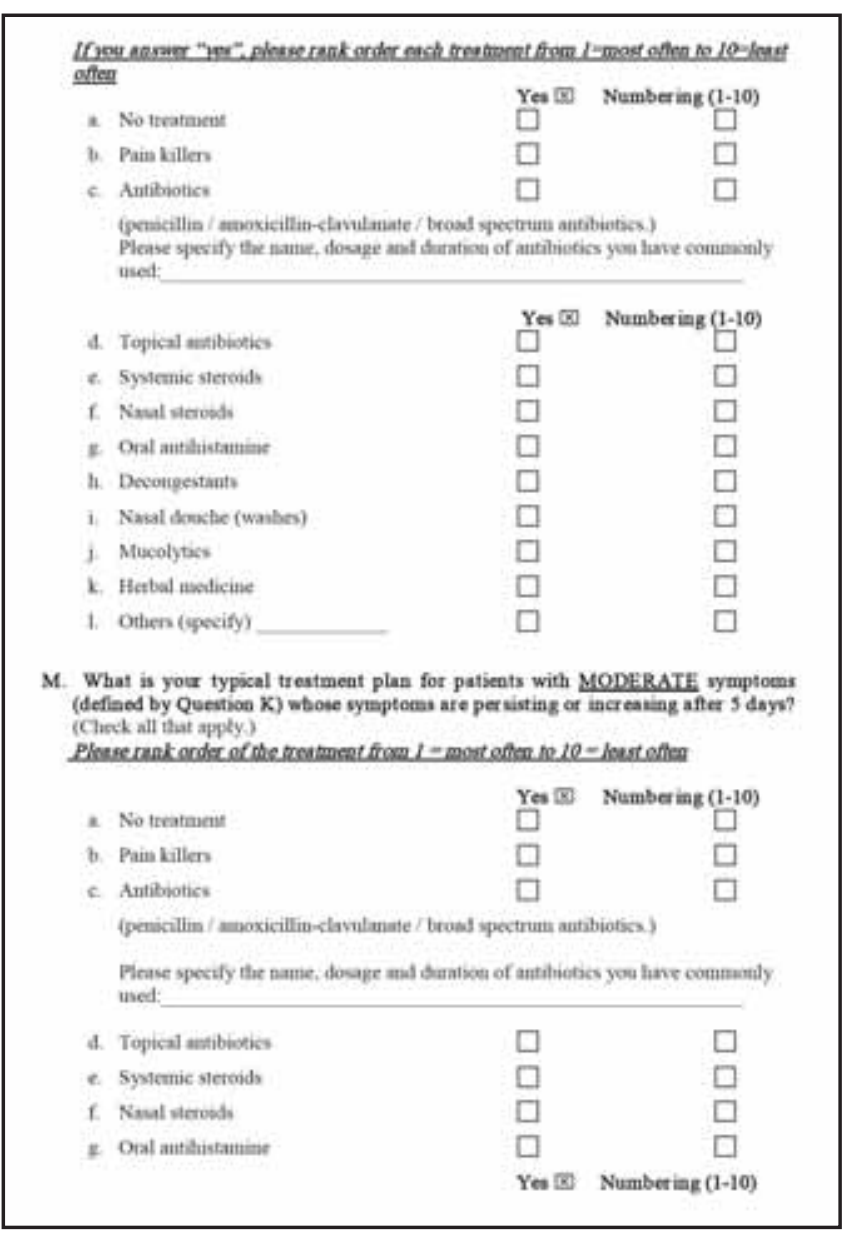

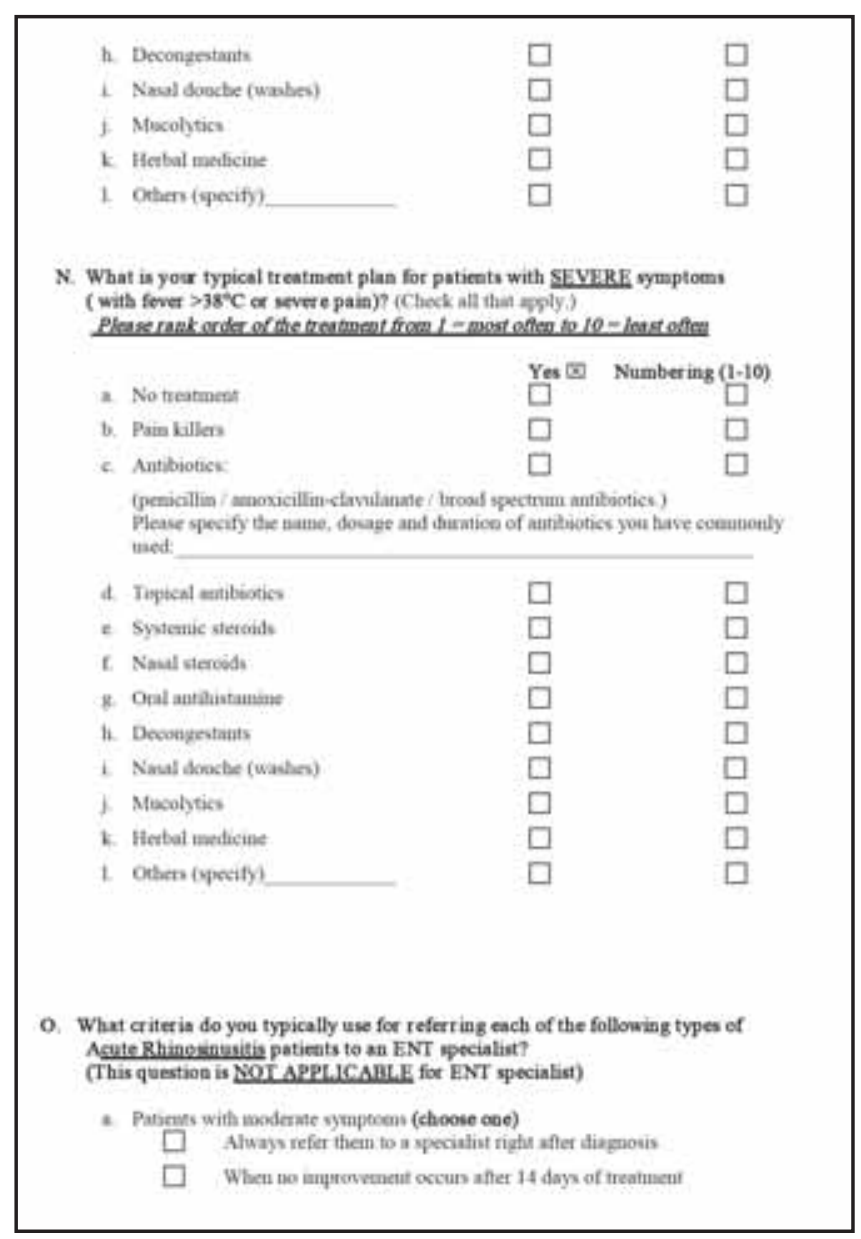

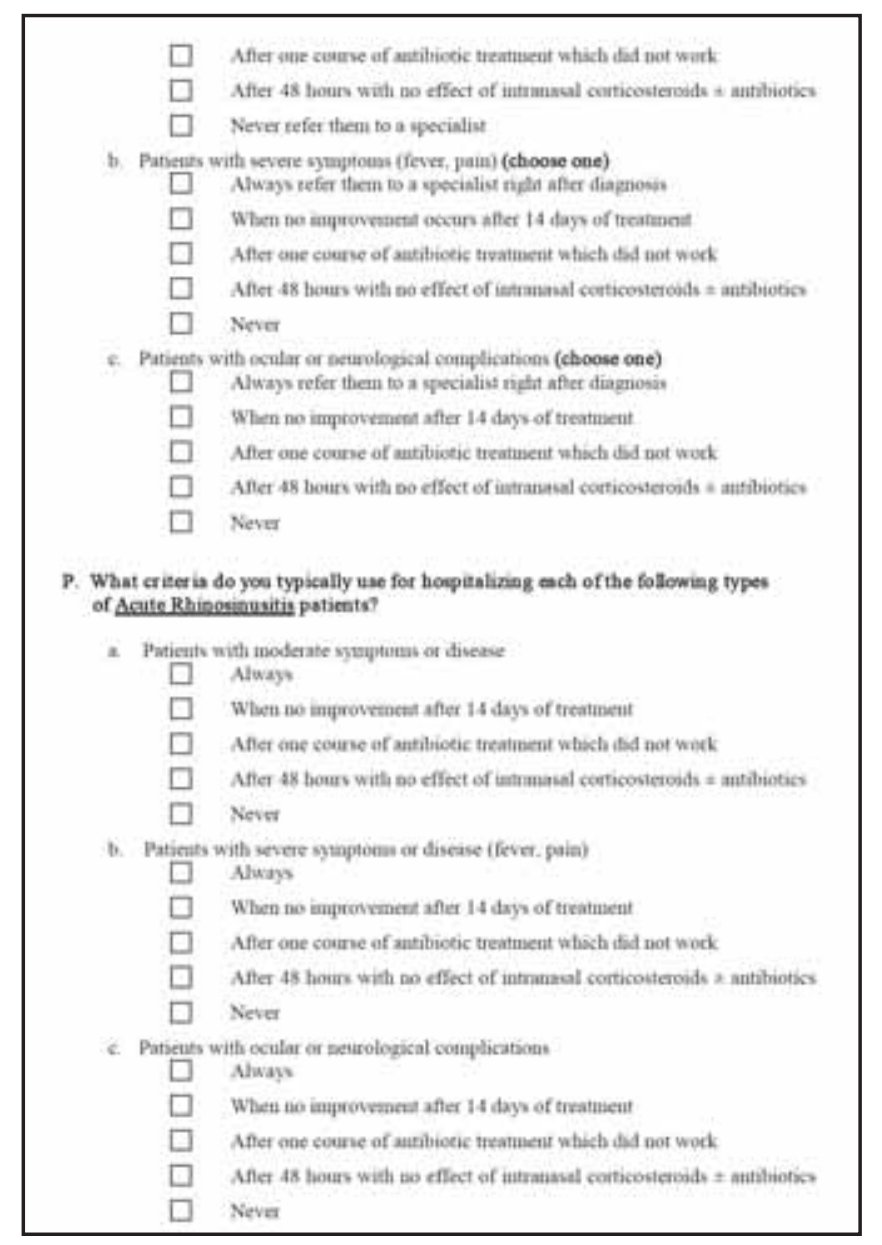

